\title{
Polarization of membrane associated proteins in the choroid plexus epithelium from normal and s/c4a10 knockout mice
}

\author{
Inga B. Christensen, Tua Gyldenholm, Helle H. Damkier and Jeppe Praetorius*
}

Department of Biomedicine, Faculty of Health, Aarhus University, Aarhus, Denmark

Edited by:

Mark O. Bevensee, University of

Alabama at Birmingham, USA

\section{Reviewed by:}

Michael Tamkun, Colorado State

University, USA

Seth L. Alper, Beth Israel Deaconess

Medical Center, USA

Ira Kurtz, University of California,

Los Angeles, USA

*Correspondence:

Jeppe Praetorius, Department of Biomedicine, Faculty of Health,

Aarhus University, Wilhelm Meyers Allé 3, DK-8000 Aarhus C, Denmark e-mail: jp@ana.au.dk
The choroid plexus epithelium (CPE) has served as a model-epithelium for cell polarization and transport studies and plays a crucial role for cerebrospinal fluid (CSF) production. The normal luminal membrane expression of $\mathrm{Na}^{+}, \mathrm{K}^{+}$-ATPase, aquaporin- 1 and $\mathrm{Na}^{+} / \mathrm{H}^{+}$ exchanger 1 in the choroid plexus is severely affected by deletion of the s/c4a10 gene that encodes the bicarbonate transporting protein Ncbe/NBCn2. The causes for these deviations from normal epithelial polarization and redistribution following specific gene knockout are unknown, but may be significant for basic epithelial cell biology. Therefore, a more comprehensive analysis of cell polarization in the choroid plexus is warranted. We find that the cytoskeleton in the choroid plexus contains $\alpha L_{-}, \alpha \mid l-, \beta l-$, and $\beta \|$-spectrin isoforms along with the anchoring protein ankyrin-3, most of which are mainly localized in the luminal membrane domain. Furthermore, we find $\alpha$-adducin localized near the plasma membranes globally, but with only faint expression in the luminal membrane domain. In s/c4a10 knockout mice, the abundance of $\beta 1 \mathrm{Na}^{+}, \mathrm{K}^{+}$-ATPase subunits in the luminal membrane is markedly reduced. Anion exchanger 2 abundance is increased in s/c4a10 knockout and its anchor protein, $\alpha$-adducin is almost exclusively found near the basolateral domain. The $\alpha \mathrm{l}$ - and $\beta \mathrm{l}$-spectrin abundances are also decreased in the s/c4a10 knockout, where the basolateral domain expression of $\alpha$ l-spectrin is exchanged for a strictly luminal domain localization. E-cadherin expression is unchanged in the s/c4a10 knockout, while small decreases in abundance are observed for its probable adaptor proteins, the catenins. Interestingly, the abundance of the tight junction protein claudin-2 is significantly reduced in the slc4a10 knockouts, which may critically affect paracellular transport in this epithelium. The observations allow the generation of new hypotheses on basic cell biological paradigms that can be tested experimentally in future studies.

Keywords: sodium hydrogen exchanger, sodium bicarbonate cotransporter, epithelial polarization, cytoskeleton, choroid plexus, cerebrospinal fluid

\section{INTRODUCTION}

The cellular monolayer of the choroid plexus produces the majority of the cerebrospinal fluid (CSF) by highly efficient transepithelial movement of solutes and water molecules (Damkier et al., 2013). CSF secretion relies on the concerted action of a variety of channels, pumps, and cotransporters situated in either the luminal plasma membrane, the basolateral plasma membrane, or in the tight junctions of the choroid plexus epithelium (CPE). The surface area of the luminal membrane of CPE is enlarged by extensive microvilli and the basolateral membrane is characteristically enlarged by basolateral infoldings referred to as the basal labyrinth. The distribution of most of the proteins in the CPE is highly conserved among studied mammalians, and even among some non-mammalian vertebrates, and is strikingly different from most other transporting epithelia. Most prominently, the $\mathrm{Na}^{+}, \mathrm{K}^{+}$-ATPase is expressed exclusively in the luminal membrane in the CPE (Zeuthen and Wright, 1978; Masuzawa et al., 1984). This is also the unusual localization of NKCC1 (Plotkin et al., 1997; Wu et al., 1998), whereas other proteins such as AE2 have a normal membrane distribution
(Lindsey et al., 1990). A variety of $\mathrm{Na}^{+}$-dependent acid/base transporters are expressed in the CPE and are expected to play central roles in CSF secretion and its $\mathrm{pH}$ regulation (Damkier et al., 2010).

The $\mathrm{Na}^{+}$driven acid/base transport proteins belong to two gene families, namely the solute carrier families 4 and 9 . The $\mathrm{Na}^{+}$-dependent $\mathrm{HCO}_{3}^{-}$transporters are encoded by slc4a4 (NBCe1), slc4a5 (NBCe2), slc4a7 (NBCn1), slc4a8 (NDCBE), and slc4a10 (Ncbe/NBCn2). Of these, NBCe2 is expressed in the luminal membrane of the CPE (Bouzinova et al., 2005), Ncbe in the basolateral membrane (Praetorius et al., 2004), and $\mathrm{NBCn} 1$ in either the luminal or basolateral membrane depending on the species or strain (Praetorius et al., 2004; Praetorius and Nielsen, 2006). A recent report suggests that the slc4a11 gene product $(\mathrm{NaBCl})$ is a $\mathrm{Na}^{+}$permeable $\mathrm{pH}_{i}$ regulator (Ogando et al., 2013). $\mathrm{NaBC1}$ is expressed in the luminal membrane of the CPE (Damkier et al., 2007). The $\mathrm{Na}^{+} / \mathrm{H}^{+}$exchangers are encoded by the slc9a1-9 genes. Only NHE1 (slc9a1) is expressed in the CPE, where it is confined to the luminal membrane (Damkier et al., 2009). This is a 
highly atypical position for this almost ubiquitously expressed protein.

Membrane proteins are sorted and trafficked to the various membrane domains from the trans-Golgi apparatus and through common recycling endosomes. The membrane proteins are delivered to the specific plasma membrane domains by vesicular transport, and retained in the membrane by anchoring proteins linking the membrane protein to the cytoskeleton (Bryant and Mostov, 2008; Mellman and Nelson, 2008). In most epithelia, the $\mathrm{Na}^{+}, \mathrm{K}^{+}$-ATPase is linked to the spectrin cytoskeleton through ankyrins and thus, all these proteins accumulate in the basolateral cell domain (Morrow et al., 1989; Nelson and Hammerton, 1989). In the CPE, the general spectrin cytoskeleton and undefined ankyrins are found primarily near the luminal membrane as opposed to most other polarized epithelia (Marrs et al., 1993; Alper et al., 1994). It is unknown whether the atypical distribution of the membrane proteins in the CPE is caused by cell type specific distribution of cytoskeletal proteins, anchoring proteins, membrane proteins, or other factors. Candidate proteins include the various spectrin isoforms, ankyrins, catenins, adducins, ERM proteins, as well as the $\mathrm{Na}^{+}, \mathrm{K}^{+}$-ATPase, NKCC1, and NHE1.

We have previously shown that the distribution of certain membrane proteins in the CPE is prominently altered in slc4a10 knockout mice (slc4a10 ko) compared to wild type (wt) littermates: In slc4a10 ko mice, NHE1 is localized to the basolateral membrane, and ezrin that usually anchors NHE1 to the actin cytoskeleton, is distributed within the cytoplasm and less in the luminal membrane (Damkier et al., 2009). In the same mouse model, the expression levels of $\mathrm{Na}^{+}, \mathrm{K}^{+}$-ATPase and the water channel AQP1 is markedly decreased, while NBCn1 and NBCe2 expression is unaffected (Damkier et al., 2009; Damkier and Praetorius, 2012).

The many unknown aspects regarding the anchor protein distribution and possible interactions between membrane proteins and anchor proteins warrant a more systematic and exhaustive approach to uncover the causes and consequences for the CPE polarization. In such studies, we regard the slc4a10 ko mouse model a useful tool. In the current study, we aimed to (1) define the spectrin and ankyrin isoforms in the CPE, (2) determine the distribution of E-cadherin, adducin, and catenin proteins, and (3) describe the cellular polarization of major membrane proteins and their anchoring proteins in CPE from slc4a10 ko and wt mice.

\section{MATERIALS AND METHODS ANIMALS}

The breeding and genotyping of mouse models deficient in slc4a10 have previously been described (Jacobs et al., 2008). Mice were bred on c57bl/6 background, and female and male mice littermates aging 4-5 weeks were used in an $\sim 50: 50$ ratio. All procedures conformed to Danish animal welfare regulations. The authors are licensed to breed the mouse strains by The Animal Experiments Inspectorate, Ministry of Food, Agriculture and Fisheries (j.n. 2012-15-2935-00004).

\section{IMMUNOHISTOCHEMISTRY}

All mice were perfusion fixed in succession via the heart with 3\% paraformaldehyde in a phosphate-buffered salt solution (PBS, in
mM: $167 \mathrm{Na}^{+}, 2.8 \mathrm{H}_{2} \mathrm{PO}_{4}^{-}, 7.2 \mathrm{HPO}_{4}^{2-}$; $\left.\mathrm{pH} 7.4\right)$. After fixation the brain was removed, post-fixed for $2 \mathrm{~h}$, dehydrated, and embedded in paraffin wax, enabling $2 \mu \mathrm{m}$ sections to be cut using a rotary microtome (Leica). The sections were de-waxed and stepwise rehydrated, before epitopes were retrieved by boiling the sections in $10 \mathrm{mM}$ Tris buffer ( $\mathrm{pH} 9$ ) with $0.5 \mathrm{mM}$ EGTA. The epitopes were quenched with $50 \mathrm{mM} \mathrm{NH}_{4} \mathrm{Cl}$ in $\mathrm{PBS}$, and unspecific binding was blocked by washing with $1 \%$ BSA in PBS with $0.2 \%$ gelatin and $0.05 \%$ saponin. Sections were incubated overnight at $4^{\circ} \mathrm{C}$ with primary antibody diluted in $0.1 \%$ BSA in PBS added $0.3 \%$ Triton X-100. Primary antibodies are listed in Table 1, and positive control tissues included kidneys, brain, vasculature, and red blood cells (not shown).

For bright-field light microscopy, the sections were incubated in horseradish peroxidase-conjugated secondary antibodies (DAKO, Glostrup, Denmark) diluted in PBS with BSA and Triton X-100. The staining was visualized using $0.05 \% 3,3^{\prime}$ diaminobenzidine tetrahydrochloride dissolved in PBS with $0.1 \%$ $\mathrm{H}_{2} \mathrm{O}_{2}$. Mayer's hematoxylin was used for counterstaining, and the sections were dehydrated in graded alcohol and xylene. Finally, sections were mounted in Eukitt mounting medium (O. Kindler, Freiburg, Germany). The images were acquired using a Leica DMRE bright-field microscope equipped with a Leica DM300 digital camera. For fluorescence visualization of the primary antibodies, AlexaFlour 488- or 555-coupled donkey anti-goat, -sheep, -rabbit, or -mouse secondary antibodies (Invitrogen)

\section{Table 1 | Primary antibodies applied in the study.}

\begin{tabular}{|c|c|c|c|}
\hline Target & Antibody & Host & Source \\
\hline$\gamma$-actin & LS-C34852 & Sheep & LifeSpan \\
\hline$\alpha$-adducin & sc-25731 (H-100) & Rabbit & Santa Cruz Biotech \\
\hline$\beta$-adducin & sc-25732 (H-120) & Rabbit & Santa Cruz Biotech \\
\hline$\gamma$-adducin & sc-25733 (H-60) & Rabbit & Santa Cruz Biotech \\
\hline $\begin{array}{l}\text { Anion } \\
\text { exchanger } 2\end{array}$ & c-terminal AE2 & Rabbit & $\begin{array}{l}\text { Stuart-Tilley (Stuart-Tilley } \\
\text { et al., 1994) }\end{array}$ \\
\hline Ankyrin-1 & sc-12733 (8C3) & Mouse & Santa Cruz Biotech \\
\hline Ankyrin-2 & LS-C11198 & Mouse & LifeSpan \\
\hline Ankyrin-3 & sc-28561 (H-215) & Rabbit & Santa Cruz Biotech \\
\hline$\alpha$-catenin & LS-B4457 & Goat & LifeSpan \\
\hline$\beta$-catenin & sc-7199 (H-102) & Rabbit & Santa Cruz Biotech \\
\hline Claudin-2 & SAB4503544 & Rabbit & Sigma \\
\hline E-cadherin & 610181 & Mouse & BD Biosciences \\
\hline Ezrin & sc-6409 (C-15) & Goat & Santa Cruz Biotech \\
\hline Moesin & ab50007 & Mouse & Abcam \\
\hline $\begin{array}{l}\text { a1 } \mathrm{Na}^{+}, \mathrm{K}^{+}- \\
\text {ATPase }\end{array}$ & & Mouse & $\begin{array}{ll}\text { Kashgarian } & \text { (Kashgarian } \\
\text { et al., 1985) }\end{array}$ \\
\hline $\begin{array}{l}\beta 1 \mathrm{Na}^{+}, \mathrm{K}^{+}- \\
\text {ATPase }\end{array}$ & & Rabbit & $\begin{array}{l}\text { Martín-Vasallo (Gonzalez- } \\
\text { Martinez et al., 1994) }\end{array}$ \\
\hline$\alpha$-spectrin & LS-C137722 & Rabbit & LifeSpan \\
\hline all-spectrin & sc-46696 (C-11) & Mouse & Santa Cruz Biotech \\
\hline$\beta \mid$-spectrin & LS-C138700 & Rabbit & LifeSpan \\
\hline$\beta \|$-spectrin & sc-28272 (H-125) & Rabbit & Novus \\
\hline$\beta$ III-spectrin & sc-28273 (H-70) & Rabbit & Santa Cruz Biotech \\
\hline$\beta I V$-spectrin & LS-B5099 & Goat & LifeSpan \\
\hline$\beta \bigvee$-spectrin & sc-104664 (C-13) & Goat & Santa Cruz Biotech \\
\hline Syntaxin-3 & sc-47437 (N-17) & Goat & Santa Cruz Biotech \\
\hline
\end{tabular}


were used, and cell nuclei were visualized using Topro3 counterstaining (Invitrogen). Sections were mounted with a coverslip in Glycergel antifade medium (DAKO) and analyzed using a Leica DMIRE2 inverted microscope with a TC5 SPZ confocal unit using $\times 63 / 1.32$ NA or $\times 100 / 1.4$ NA HCX PI Apo objectives with 8 -bit depth for illustration of localization and colocalization, while 12bit image depth was applied for fluorescence semiquantitation.

\section{SEMIQUANTITATION OF IMMUNOFLUORESCENCE SECTIONS}

Specific protein abundance was investigated by quantifying the immunofluorescence intensities from confocal micrographs. All tissues were carefully handled in parallel from the time of fixation throughout embedding, sectioning, staining, and imaging. To avoid saturation of the photomultiplier, the intensity dynamic range (gain and offset) was adjusted to span the intensities of the most intense sample for each antibody. Images were acquired in the focal plane with the highest signal intensity using fixed settings for magnification, laser power, gain, image depth, offset, and averaging for all images with a given antibody.

The immunofluorescence intensities of the stained choroid plexuses were quantified from 12-bit gray scale images using Image Pro (Media Cybernetics). For each image, the area of interest was manually defined to avoid counts from nonchoroidal tissue or artifacts. For all quantifications, the number of cell nuclei within the area of interest was automatically counted with fixed settings for minimal cell nucleus area, density/intensity signal, smoothing, and intensity range. The sum of immunofluorescence intensities was then divided by the number of nuclei to normalize for differences in choroid plexus tissue size among the sections. All analyzed images were from 4th ventricle choroid plexus, and data from the right and left brain sections were averaged for each animal when possible. In bar graphs, data are normalized to the mean wild type fluorescence signal. Where indicated, linescan intensity profiles were generated from fluorescence micrographs using Image Pro. The lines of interest are marked in white on the respective micrographs and represent only examples of juxta-labyrinth profiles from the indicated line.

\section{STATISTICAL ANALYSIS}

Data is expressed as means \pm sem. A non-parametric test (Mann-Whitley-Wilcox rank sum test) was used to compare two groups. Values of $p<0.05$ were considered statistically significant. Each $n$ represents one animal.

\section{RESULTS}

\section{THE CHOROID PLEXUS EPITHELIUM EXPRESSES ANKYRIN-3 AND $\alpha \mathrm{I}-$,} $\alpha$ II-, $\beta I-$, AND $\beta$ II-SPECTRINS

The $\mathrm{Na}^{+}$independent $\mathrm{HCO}_{3}^{-}$exchanger AE2, as well as the $\mathrm{Na}^{+}, \mathrm{K}^{+}$-ATPase, is typically linked to the spectrin cytoskeleton via anchoring proteins, such as ankyrins, in the basolateral membrane. In the CPE, however, the $\alpha 1$ subunit of the $\mathrm{Na}^{+}, \mathrm{K}^{+}$ATPase is expressed in the luminal brush border, along with the $\beta 1$ subunit of the $\mathrm{Na}^{+}, \mathrm{K}^{+}$-ATPase (Figure 1A, left and right panels, respectively). AE2 is located in the basolateral plasma membrane, similar to other epithelia (Figure 1B, left panel).
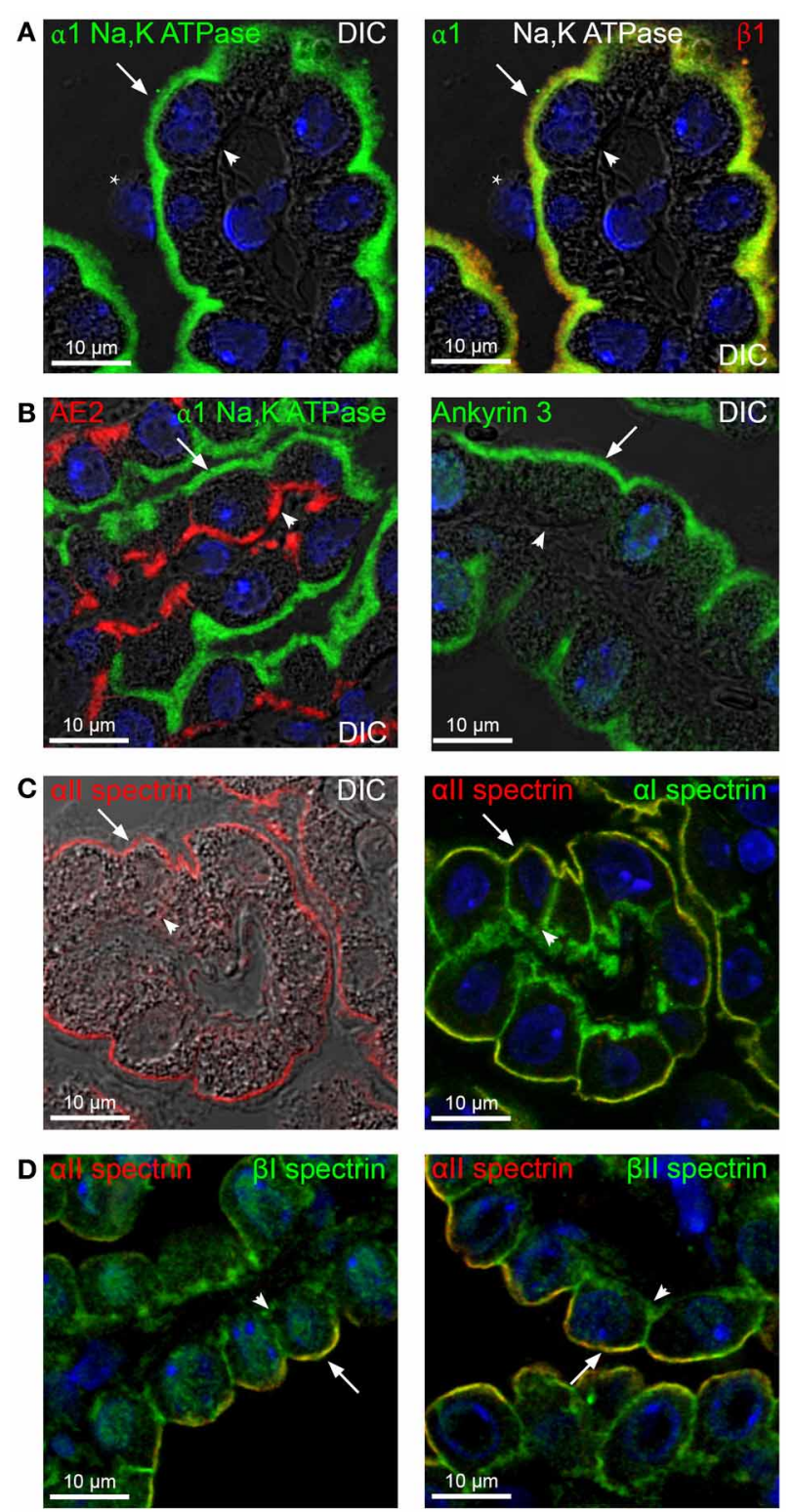

FIGURE 1|Expression of spectrins and ankyrins in the choroid plexus epithelium. Mouse brain sections were immunostained for $\mathrm{Na}^{+}, \mathrm{K}^{+}$-ATPase $\alpha 1$ subunit, and ankyrins $1-3, \alpha \mathrm{I}-\mathrm{Il}$ and $\beta \mathrm{I}-\mathrm{V}$ spectrins (in green), as well as $\mathrm{Na}^{+}, \mathrm{K}^{+}$-ATPase $\beta 1$ subunit and AE2 (in red). Yellow color indicates co-localization. (A) Immunohistochemical staining for $\mathrm{Na}^{+}, \mathrm{K}^{+}$-ATPase a1 subunit overlaid on differential interference contrast image (DIC, left panel). The same section was doublestained for $\mathrm{Na}^{+}, \mathrm{K}^{+}$-ATPase $\alpha 1$ and $\beta 1$ subunits (right panel). ${ }^{*}$ marks an apparent macrophage (Kolmer cell). (B) Double immunofluorescence staining for $\mathrm{AE} 2$ and $\mathrm{Na}^{+}, \mathrm{K}^{+}$-ATPase $\alpha 1$ (left panel), and immunohistochemical detection of ankyrin-3 with DIC (right panel). (C) Immunostaining for all-spectrin overlaid on the corresponding DIC image (left panel). Double immunofluorescence detection of $\alpha$ ll-spectrin and $\alpha$-spectrin (right panel). (D) Immunolabeling for $\beta \mid$ and $\beta$ Il-spectrins (left and right panel, respectively) in doublelabeling with $\alpha$ ll-spectrin. Arrows indicate the luminal membrane, while arrowheads indicate the basolateral membrane. Cell nuclei were visualized by Topro nuclear staining (blue). 
As the expression of spectrin and ankyrin isoforms in the CPE have not been determined, a panel of antibodies reacting specifically against ankyrins 1-3, spectrins $\alpha$ I-II, and spectrins $\beta \mathrm{I}-\mathrm{V}$ were employed for immunohistochemical analysis of the CPE. As illustrated in Figure 1B (right panel), ankyrin-3 immunoreactivity was predominantly observed in close proximity to the luminal membrane and in microvilli. No other ankyrins were localized to the CPE with the applied antibodies but did label control tissues (not shown).

The $\alpha$ II-spectrin immunoreactivity was mainly observed in the luminal membrane domain (Figure 1C, left panel). However, $\alpha \mathrm{I}$-spectrin immunoreactivity was most prominent in relation to the basal labyrinth and to a lesser extent in the luminal membrane domain of the CPE cells (Figure 1C, right panel). $\beta \mathrm{I}$ - and $\beta$ II-spectrin specific antibodies also produced a mainly luminal staining pattern with minor staining in relation to the lateral membrane and basal labyrinth (Figure 1D, left and right panels, respectively). The $\beta$ II-spectrin labeling was also observed in a supra-nuclear location, where the microtubule organizing center is situated in CPE cells (see Figure 8). No other spectrin antibodies reacted with the CPE (not shown). The CPE expresses ankyrin-3, $\alpha$ II-spectrin, $\beta I$-spectrin, and $\beta I I-s p e c t r i n$ in high abundance beneath the luminal membrane and the three spectrins at a lesser extent in proximity to the basal labyrinth. In contrast, the fourth spectrin expressed in the CPE, aI-spectrin, shows an opposite expression pattern, with most expression in the basolateral labyrinth and minor in the luminal membrane. In regard to the different cellular localizations, AE2 is unlikely to bind ankyrins in the choroid plexus.

\section{E-CADHERIN, $\alpha$ - AND $\beta$-CATENIN ARE CO-EXPRESSED IN THE BASOLATERAL DOMAIN}

The basolateral adhesion molecule E-cadherin is known to link the cytoskeleton through either ankyrins or catenins. From Figure 1B (right panel), it appears that ankyrin-3 would be an unlikely anchor for E-cadherin as it is located near the luminal membrane. Figure 2A shows that E-cadherin localizes to the basolateral membrane domain of the $\mathrm{CPE}$, opposite ankyrin3 in the luminal membrane domain. As shown in Figure 2B, $\alpha$ - and $\beta$-catenin immunoreactivity is also pronounced in the basolateral domain. Both $\alpha$-catenin and $\beta$-catenin is known to link to the actin cytoskeleton. Figure $2 \mathrm{C}$ shows a predominant luminal membrane domain immunolabeling for $\gamma$-actin, which extends into the microvilli. Thus, in the CPE, it seems more likely that E-cadherin is linked to the general actin cytoskeleton through catenins rather than through ankyrin-3 and spectrins.

\section{THE CHOROID PLEXUS DISPLAYS A TYPICAL EPITHELIAL ADDUCIN EXPRESSION PATTERN}

Adducins are alternatives to ankyrins for linking AE2 to the cytoskeleton at the basolateral membrane of the choroid plexus, as they co-sediment separately from ankyrin and the $\mathrm{Na}^{+}, \mathrm{K}^{+}$ATPase in sucrose gradients (Marrs et al., 1993). Adducins bind both the spectrin and actin cytoskeleton and adducin immunoreactivity was previously shown in proximity to AE2 in the CPE (Alper et al., 1994). Adducin forms dimers consisting of $\alpha-\beta$ or $\alpha$ $\gamma$ subunits. The brain sections were immunostained for the three
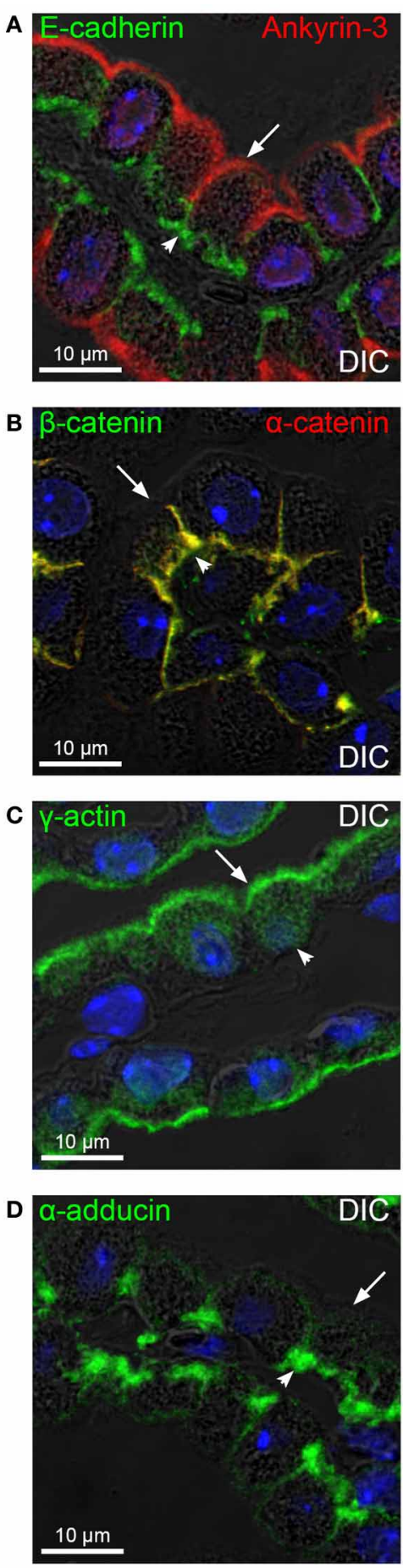

FIGURE 2 | Expression of E-cadherin, catenins, $\boldsymbol{\gamma}$-actin, and $\alpha$-adducin in the CPE. Mouse brain sections were immunostained for E-cadherin, $\beta$-catenin, $\gamma$-actin, and $\alpha$-adducin (in green), as well as ankyrin- 3 and $\alpha$-catenin (in red). (A) Immunohistochemical double immunolabeling for E-cadherin and ankyrin-3 overlayed on the corresponding DIC image. (B) Double immunolabeling for $\alpha$ - and $\beta$-catenin, overlaid on the corresponding DIC image. (C,D) Immunolabeling and DIC images for $\gamma$-actin and $\alpha$-adducin, respectively. Arrows indicate the luminal membrane, while arrowheads indicate the basolateral membrane. Cell nuclei were visualized by Topro nuclear staining (blue) 
adducin forms in order to establish their relative locations in the CPE. The $\alpha$-adducin immunoreactivity was observed near both the luminal and basolateral membrane (Figures 2D, 3A), with highest reactivity at the basal labyrinth as expected.

Immunofluorescence staining for $\beta$-adducin and $\gamma$-adducin failed, but peroxidase stained sections are seen in Figures 3B,C, respectively. Antibodies against $\beta$-adducin yielded staining in the luminal domain, while $\gamma$-adducin staining was more pronounced toward the basolateral cell domain. Despite the variable performance of the adducin antibodies, the cellular distribution of adducins in CPE seems comparable to what is observed in renal epithelia (not shown). Syntaxin-3 is a typical luminal membrane SNARE protein (Mellman and Nelson, 2008), which ascertains the insertion of specific vesicles destined to this part of the plasma membrane. Figure 3D shows that syntaxin-3 is also a luminal membrane protein in CPE. Commercially available antibodies against the basolateral SNARE protein syntaxin-4 did not produce reliable immunostaining in CPE or control epithelia (not shown).

\section{MOESIN DOES NOT REDISTRIBUTE TO THE BASOLATERAL MEMBRANE IN THE CHOROID PLEXUS OF s/c4a10 KO MICE}

Previously, we have characterized the slc4a10 ko mouse (Jacobs et al., 2008) and showed that the cellular localization of NHE1 in these mice was found in the basolateral plasma membrane instead of in the luminal membrane as in the slc4a10 wt mouse (Damkier et al., 2009). Therefore, antibodies reacting specifically against the ezrin and moesin proteins known to interact with NHE1 directly or indirectly were used for immunohistochemical analysis of CPE. As previously observed, ezrin staining is found in the cytoplasm close to the luminal plasma membrane in the wt CPE (Figure 4A, micrographs). Ezrin staining was more variable among slc4a10 ko mice, but was also here found predominantly in the subluminal domain in the CPE as assessed by immunofluorescence (Figure 4B). Figure 5 shows that the ezrin distribution appears more cytosolic in slc4a10 ko mice compared to slc4a10 wt in peroxidase stained sections from the same mice. Some labeling is observed in the luminal membrane domain, but the labeling is also found in intracellular compartments. The bar graph in Figure 4A shows that the semi-quantified immunofluorescence signal for ezrin did not differ between slc4a10 wt and ko mice, ( $p=0.556, n=5$ and 4 for wt and ko, respectively).

As shown in the micrographs of Figure 4C, moesin is found at the same cellular localization as ezrin, close to the luminal membrane, with no apparent difference in subcellular localization between the slc4a10 wt and ko. The bar graph shows that the moesin signal did not differ quantitatively between slc4a10 wt and ko mice ( $p=0.286, n=5$ and 4 for wt and ko, respectively). Thus, neither ezrin nor moesin colocalizes with NHE1 in slc4a10 ko mice.

\section{DECREASED EXPRESSION OF $\beta 1-\mathrm{Na}^{+}, \mathrm{K}^{+}$-ATPase BUT NOT ANKYRIN-3 IN THE sIc4a10 KO}

The $\mathrm{Na}^{+}, \mathrm{K}^{+}$-ATPase is linked to the spectrin cytoskeleton through ankyrin-3 in the choroid plexus (Marrs et al., 1993). The expression of $\alpha 1-\mathrm{Na}^{+}, \mathrm{K}^{+}$-ATPase was greatly decreased in slc4a10 ko mice (Damkier and Praetorius, 2012). Therefore, it
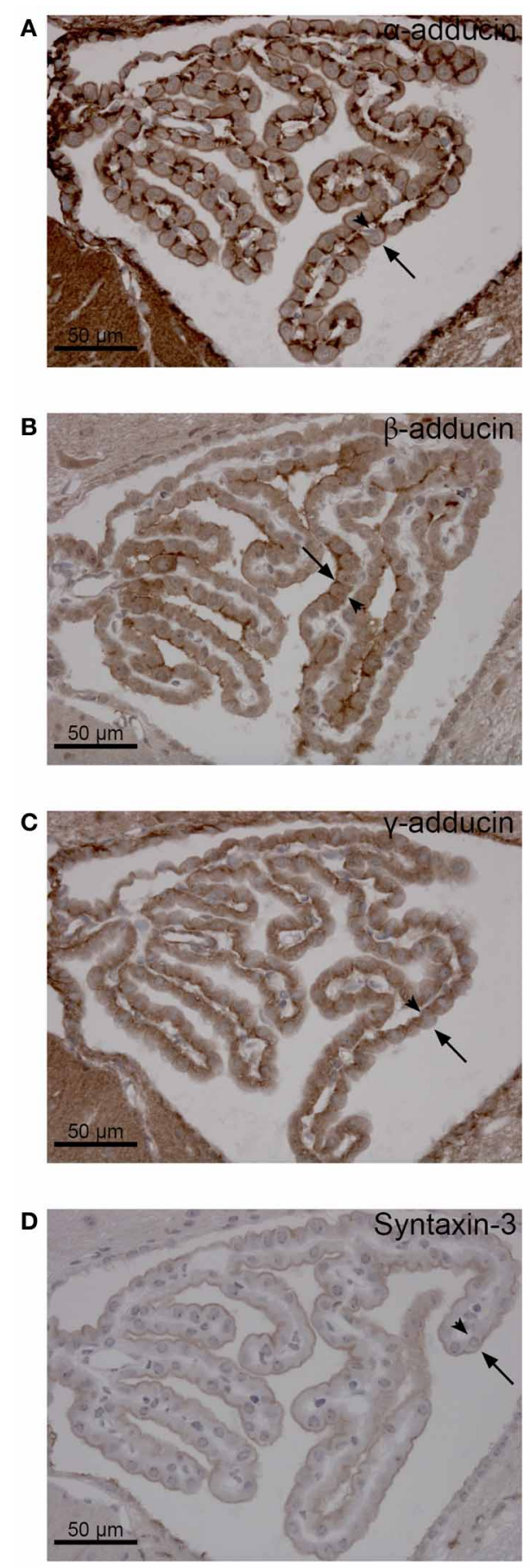

FIGURE 3 | Distribution of $\alpha-, \beta-$, and $\boldsymbol{\gamma}$-adducin in the mouse CPE.

(A-C) Peroxidase immunohistochemical localization of $\alpha^{-}, \beta-$, and $\gamma$-adducin in the normal mouse CPE, as indicated. (D) Immunostaining of the normal mouse choroid plexus for syntaxin-3. Arrows indicate the luminal membrane, while arrowheads indicate the basolateral membrane.

is feasible that the $\mathrm{Na}^{+}, \mathrm{K}^{+}$-ATPase $\beta$ subunit as well as the anchoring proteins would display similar changes in abundance or in subcellular distribution. Figure 6A illustrates that the subcellular localization of the $\beta 1-\mathrm{Na}^{+}, \mathrm{K}^{+}$-ATPase subunit is strictly 

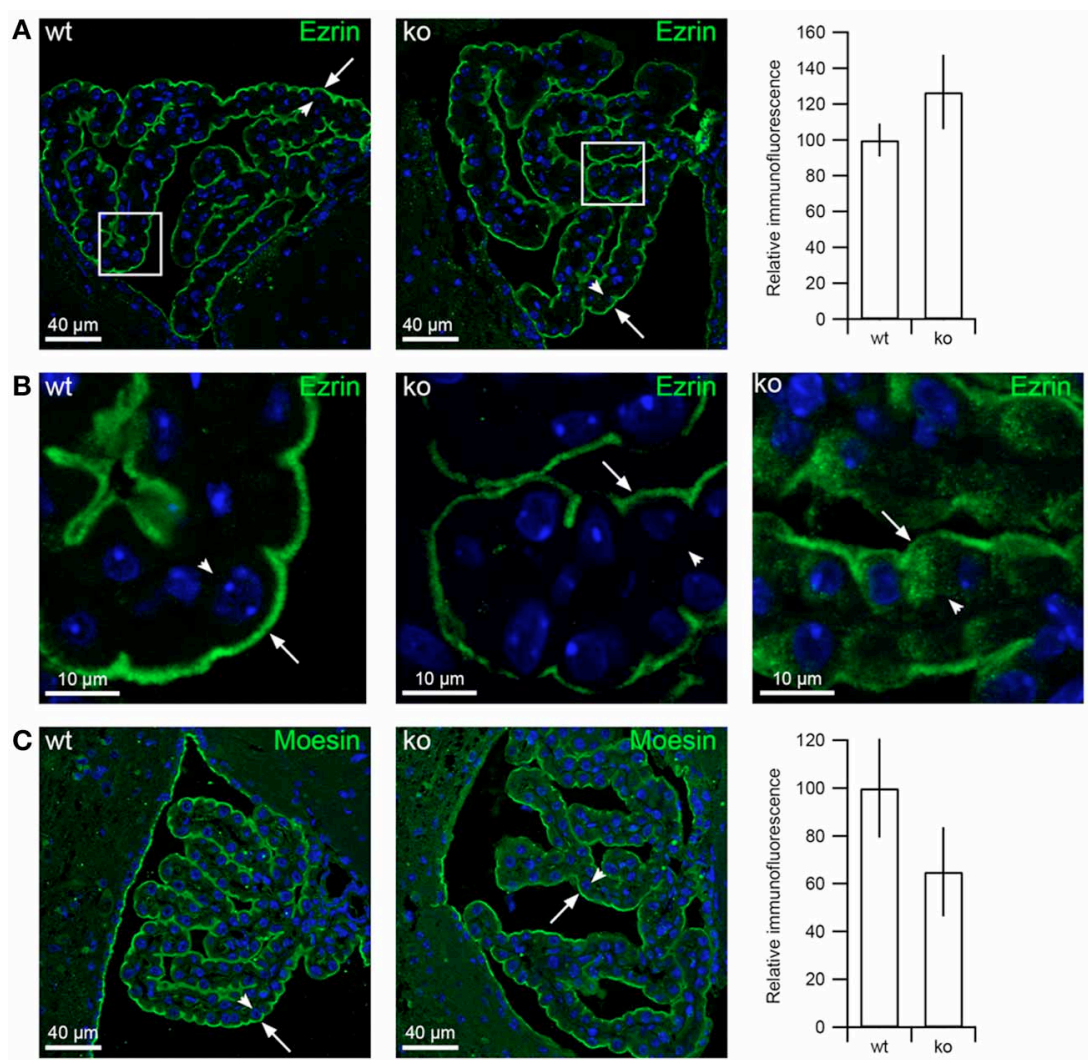

FIGURE 4 | Ezrin and moesin expression in CPE from slc4a10 wt and ko mice. Mouse brain sections were immunofluorescence stained with ezrin and moesin antibodies (in green). (A) Immunohistochemical detection of ezrin in s/c4a10 wt and ko, as indicated. Bar graph on the right show the semi-quantitation of the ezrin immunofluorescence in s/c4a10 wt and ko mouse CPE (wt: $n=5$, ko: $n=4$ ). (B) Immunohistochemical detection of ezrin at a higher magnification in slc4a10 wt and ko, as indicated. (C) Immunostaining for moesin in slc4a10 wt and ko, respectively. Bar graph on the right show the semi-quantitation of the moesin immunofluorescence in slc4a10 wt and ko mouse CPE (wt: $n=5$, ko: $n=4$ ). Arrows indicate the luminal membrane, while arrowheads indicate the basolateral membrane. Cell nuclei were visualized by Topro nuclear staining (blue).
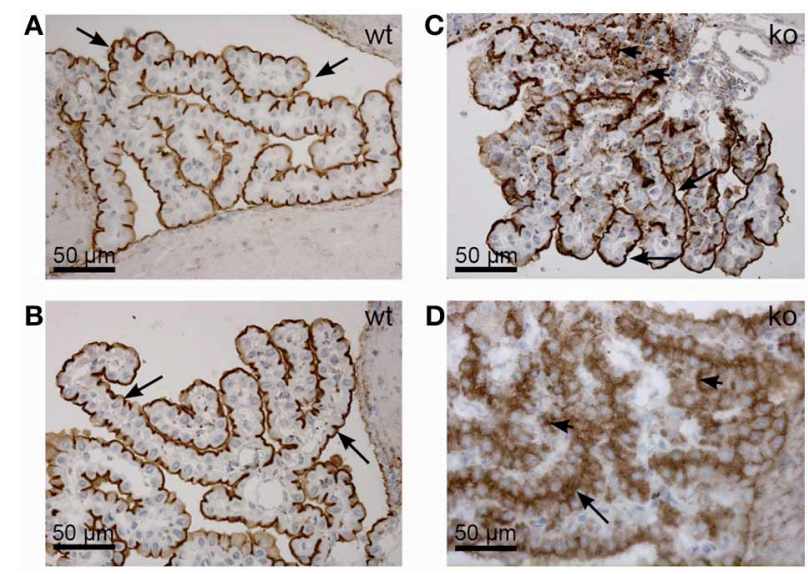

FIGURE 5 | Distribution of ezrin in the choroid plexus epithelium of slc4a 10 wt and ko mice. (A-D) Labeling of choroid plexus brain sections with peroxidase conjugated anti-ezrin antibodies from slc4a10 wt $(\mathbf{A}, \mathbf{B})$ and ko mice (C,D). The two examples from slc4a10 ko mice indicate the range of ezrin expression. Arrows indicate the luminal membrane, while arrowheads indicate the intracellular distribution of ezrin in s/c4a10 ko. luminal in CPE from both slc4a10 wt and ko mice, and that the abundance is $\sim 75 \%$ decreased in slc4a10 ko CPE (Figure 6A bar graph, $p=0.0357, n=5$ and 3 for wt and ko, respectively). Ankyrin-3 abundance seemed lower in slc4a10 ko CPE compared to wt littermates (Figure 6B, micrographs). This observation was not paralleled by a significant decrease in ankyrin-3 expression in slc4a10 ko (Figure 6B bar graph, $p=0.250, n=5$ and 3 for wt and ko, respectively). Thus, the $\beta 1-\mathrm{Na}^{+}, \mathrm{K}^{+}$-ATPase parallels the $\alpha 1-\mathrm{Na}^{+}, \mathrm{K}^{+}$-ATPase protein abundance and localization in the $\mathrm{CPE}$ of slc4a10 wt and ko mice, while the protein abundance of their colocalizing scaffolding protein ankyrin-3 is unaffected in slc4a10 ko CPE.

\section{AE2 ABUNDANCE IN THE CHOROID PLEXUS IS INCREASED IN s/c4a10 KO MICE}

The expression and localization of $\mathrm{Na}^{+}$-transporting slc4 gene family members $\mathrm{NBCn} 1$ and $\mathrm{NBCe} 2$ did not change significantly in slc4a10 ko mice (Damkier et al., 2009). However, Figure 6C shows that the abundance of AE2 encoded by slc4a 2 is increased in the CPE from slc4a10 ko mice relative to the wt mice. The semi-quantitation depicted in the bar graph indicates 

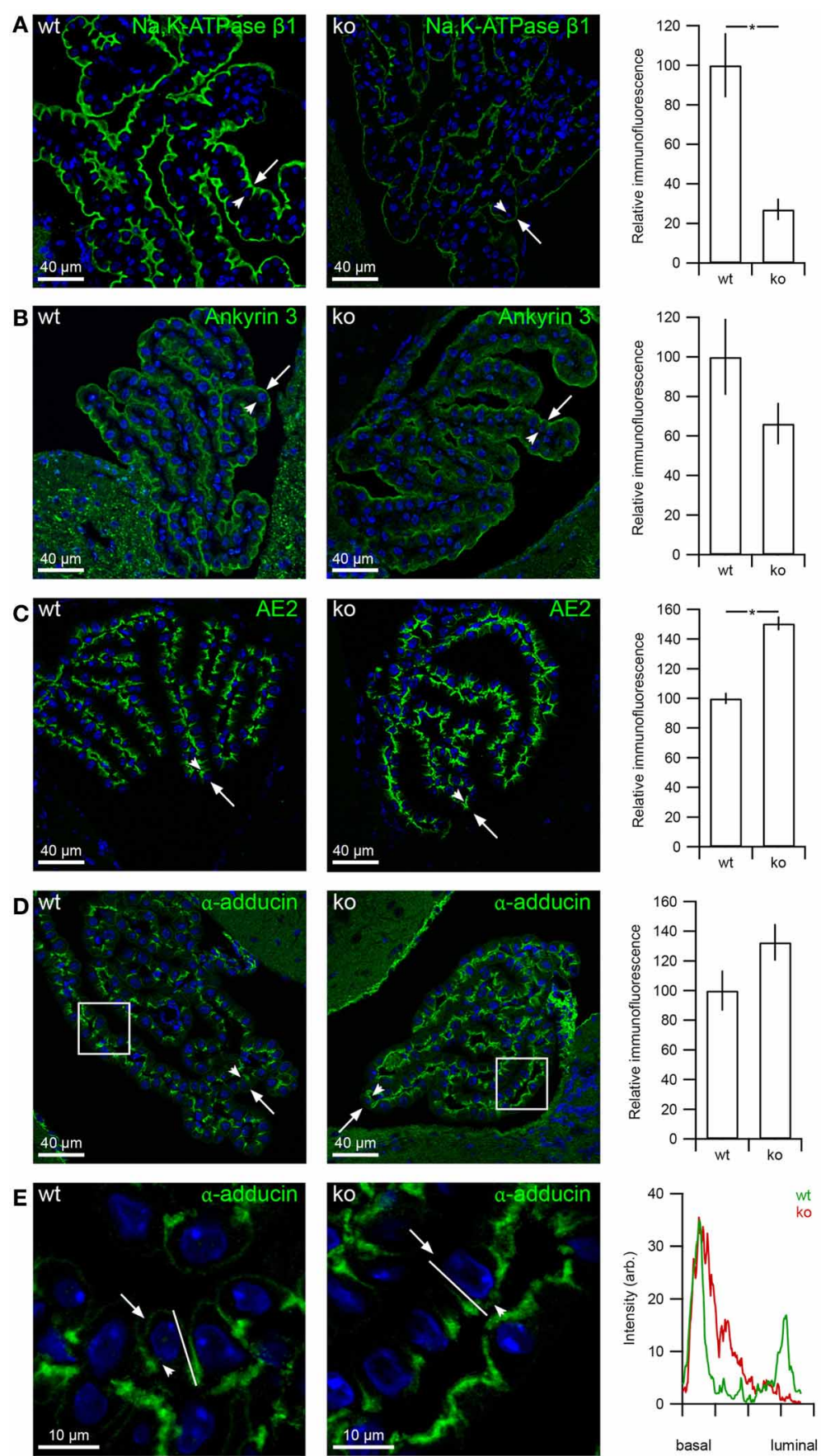

FIGURE $6 \mid \beta 1 \mathrm{Na}^{+}, \mathrm{K}^{+}$-ATPase and AE2 expression is changed in the CPE from slc4a10 ko mice. Mouse brain sections were immunostained for $\mathrm{Na}^{+}, \mathrm{K}^{+}$-ATPase $\beta 1$ subunit, ankyrin-3, AE2, and $\alpha$-adducin. (A) Immunohistochemical detection of $\beta 1-\mathrm{Na}^{+}, \mathrm{K}^{+}$-ATPase in wt and ko, as indicated. Bar graphs on the right show the semi-quantitation of the respective immunofluorescence in s/c4a10 wt and ko mouse CPE (wt: $n=5$, ko: $n=3$ ). (B) Immunostaining for ankyrin-3 in s/c4a10 wt and ko, respectively. Bar graphs on the right show the semi-quantitation of the immunofluorescence in slc4a10 wt and ko mouse CPE (wt: $n=5$, ko: $n=4$ ). (C) Immunohistochemical detection of AE2 in s/c4a10 wt and ko, as indicated. Bar graph on the right show the semi-quantification of the immunofluorescence in s/c4a10 wt and ko mouse CPE $(n=4)$. (D) Immunostaining for $\alpha$-adducin in s/c4a10 wt and ko, respectively. Bar graphs on the right show the semi-quantitation of the immunofluorescence in s/c4a10 wt and ko mouse CPE (wt: $n=5$, ko: $n=3$ ). (E) Immunohistochemical detection of $\alpha$-adducin in wt and s/c4a10 ko at a higher magnification. The histogram on the right is a linescan of the cellular fluorescence intensity from the basal to the luminal domain. The analyzed line is indicated on the two micrographs on the left. Arrows indicate the luminal membrane, while arrowheads indicate the basolateral membrane. *indicates statistical significance. Cell nuclei were visualized by Topro nuclear staining (blue). 

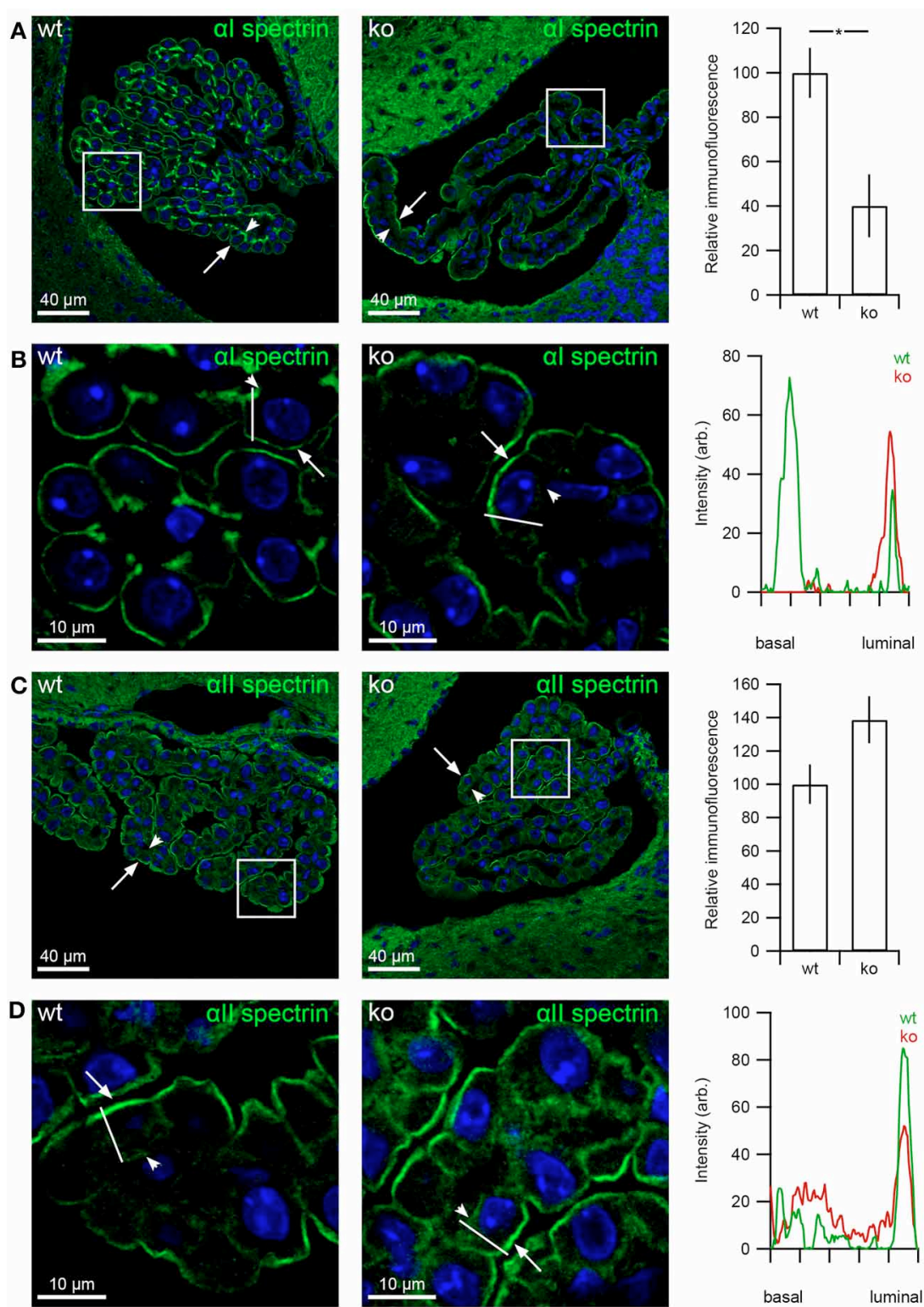

FIGURE 7 | Altered $\alpha 1$-spectrin expression in CPE from s/c4a10 ko mice. Mouse brain sections were immunostained for $\alpha \mathrm{l}$ - and all-spectrin. (A) Immunolabeling for $\alpha$-spectrin in slc4a10 wt and ko, as indicated. Bar graph on the right show the semi-quantitation of the respective immunofluorescence in s/c4a10 wt and ko mouse CPE (wt: $n=5$, ko: $n=4$ ). (B) High magnification micrograph of the subcellular al-spectrin staining pattern. The graph is a linescan of the cellular fluorescence signal from the basal to the luminal domain. The analyzed line is indicated on the micrographs. (C) Immunolabeling for all-spectrin in slc4a10 wt and ko, as indicated. Bar graph on the right show the semi-quantitation of the respective immunofluorescence in s/c4a10 wt and ko mouse CPE (wt: $n=5, k o: n=4$ ). (D) High magnification micrograph of the subcellular all-spectrin staining pattern. The graph is a linescan of the cellular fluorescence signal from the basal to the luminal domain. The analyzed line is indicated on the micrographs. Arrows indicate the luminal membrane, while arrowheads indicate the basolateral membrane. ${ }^{*}$ indicates statistical significance. Cell nuclei were visualized by Topro nuclear staining (blue). an $\sim 50 \%$ increase in the relative AE2 abundance in slc4a10 ko compared to wt ( $p=0.029, n=4$ for wt and ko). The increase in AE2 protein was not accompanied by a significant change in $\alpha$-adducin abundance in the slc4a10 ko CPE (Figure 6D, $p=$ $0.250, n=5$ and 3 for wt and ko, respectively). Nevertheless, we noted a non-significant trend toward increased total $\alpha$-adducin abundance and a more pronounced basolateral staining relative to the luminal staining intensity. The luminal immunoreactivity was almost completely absent in the $s l c 4 a 10$ ko CPE (Figure 6E).

\section{DECREASED $\alpha$ I BUT NOT $\alpha$ II, $\beta$ I, AND $\beta$ II ABUNDANCE IN THE s/c4a10 KO CPE}

The $\alpha \mathrm{I}$-spectrin immunoreactivity shows an $\sim 60 \%$ decrease in protein abundance in the slc4a10 ko compared to the 

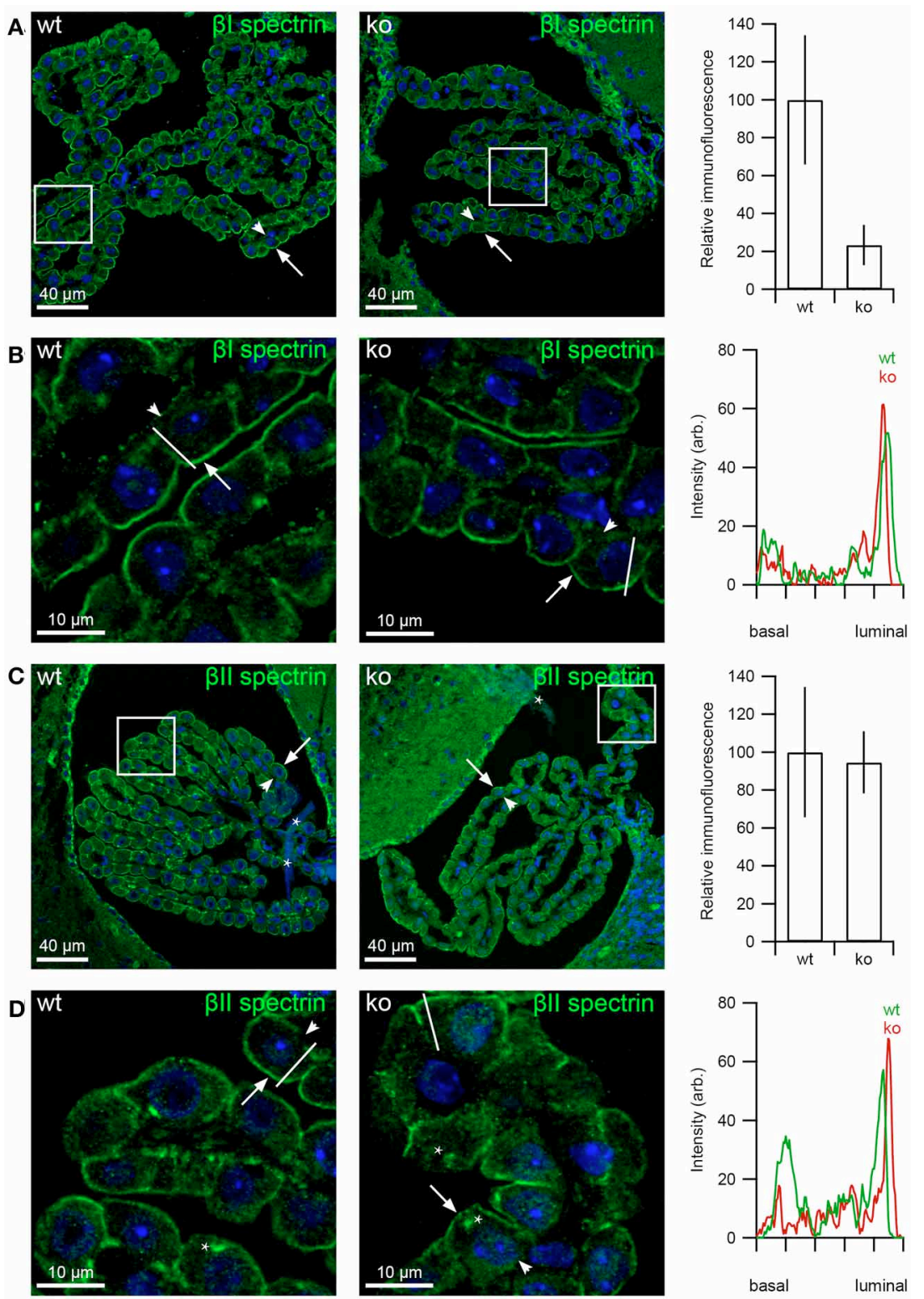

FIGURE 8 |Altered $\beta$-spectrin expression in CPE from slc4a10 ko mice. Mouse brain sections were immunostained for $\beta \mid$ - and $\beta \| l$-spectrin. (A) Immunolabeling for $\beta \mathrm{l}$-spectrin in s/c4a10 wt and ko CPE, as indicated. Bar graph on the right show the semi-quantitation of the respective immunofluorescence in slc4a10 wt and ko mouse CPE (wt: $n=5$, ko: $n=4$ ). (B) High magnification micrograph of the subcellular $\beta l$-spectrin staining pattern. The graph is a linescan of the cellular fluorescence signal from the basal to the luminal domain. The analyzed line is indicated on the micrographs. (C) Immunolabeling for $\beta / l$-spectrin in s/c4a10 wt and ko, as indicated. Bar graph on the right show the semi-quantitation of the respective immunofluorescence in slc4a10 wt vs. ko mouse CPE (wt: $n=5$, ko: $n=4)$. * denotes artifacts. (D) High magnification micrograph of the subcellular $\beta / 1$-spectrin staining pattern. * denotes supra-nuclear labeling. The graph is a linescan of the cellular fluorescence signal from the basal to the luminal domain. The analyzed line is indicated on the micrographs. Arrows indicate the luminal membrane, while arrowheads indicate the basolateral membrane. Cell nuclei were visualized by Topro nuclear staining (blue). wt (Figure 7A, $p=0.0357, n=5$ and 3 for wt and ko, respectively). This significant change in protein abundance was accompanied by a difference in cellular localization between the genotypes; from predominantly staining the basolateral labyrinth in the slc4a10 wt to almost exclusively luminal expression in the slc4a10 ko (Figure 7B). The immunofluorescence signal for $\alpha$ II-spectrin was not significantly altered in the CPE from slc4a10 ko mice as compared to wt (Figure 7C, $p=0.143, n=5$ and 3 for wt and ko, respectively). There was no apparent change in cellular localization of the protein apart from more cytosolic immunoreactivity (Figure 7D).

Analysis of the $\beta \mathrm{I}$-spectrin abundance in the CPE resulted in a non-significant decrease in the slc4a10 ko compared to wt 

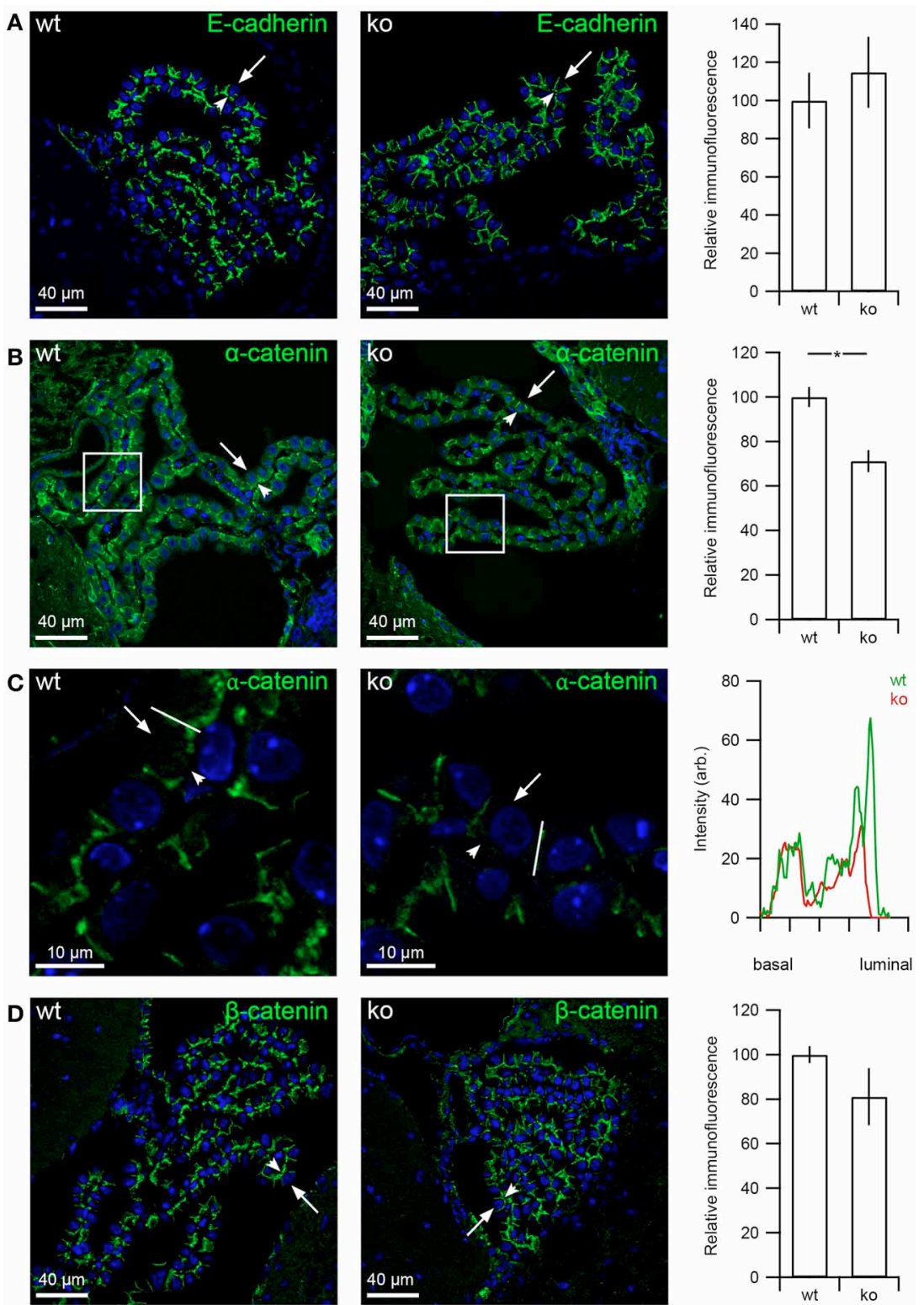

FIGURE 9 | E-cadherin, $\alpha$ - and $\beta$-catenin expression in CPE from slc4a 10 wt and ko mice. Mouse brain sections were immunostained for E-cadherin and $\alpha$ and $\beta$-catenin, as indicated. (A) Immunohistochemical detection of E-cadherin in slc4a10 wt and ko, as indicated. Bar graphs on the right show the semi-quantitation of the immunofluorescence in s/c4a $10 \mathrm{wt}$ and ko mouse CPE ( $n=4)$. (B) Immunolabeling for $\alpha$-catenin in s/c4a10 wt and ko, as indicated. Bar graph on the right show the semi-quantitation of the immunofluorescence in slc4a10 wt and ko mouse CPE (wt: $n=5$, ko: $n=3$ ). (C) High magnification micrograph of the subcellular $\alpha$-catenin staining pattern. The histogram on the right is a linescan of the cellular fluorescence intensity from the basal to the luminal domain. The analyzed line is indicated on the two micrographs on the left. (D) Immunolabeling for $\beta$-catenin in s/c4a10 wt and ko, as indicated. Bar graph on the right shows the semi-quantitation of the immunofluorescence in wt and ko mouse CPE (wt: $n=5$, ko: $n=3$ ). Arrows indicate the luminal membrane, while arrowheads indicate the basolateral membrane. ${ }^{*}$ indicates statistical significance. Cell nuclei were visualized by Topro nuclear staining (blue). mice (Figure 8A, $p=0.057, n=5$ and 3 for wt and ko, respectively), where the cellular localization did not change markedly (Figure 8B). The immunofluorescence signal for $\beta$ II-spectrin shows no difference between slc4a10 ko and wt CPE (Figure 8C, $p=0.85, n=5$ and 3 for wt and ko, respectively), whereas the cellular localization appears less basolateral in the ko mice (Figure 8D).

\section{E-CADHERIN AND $\beta$-CATENIN ABUNDANCE DOES NOT CHANGE IN THE CHOROID PLEXUS OF sIc4a10 KO MICE}

Major changes in protein abundances of E-cadherin and the catenins were not expected in the slc4a10 ko CPE, as the major changes in protein expression are observed in relation to the luminal plasma membrane. The micrographs in Figure 9A shows similar labeling intensity and cellular distribution of E-cadherin 

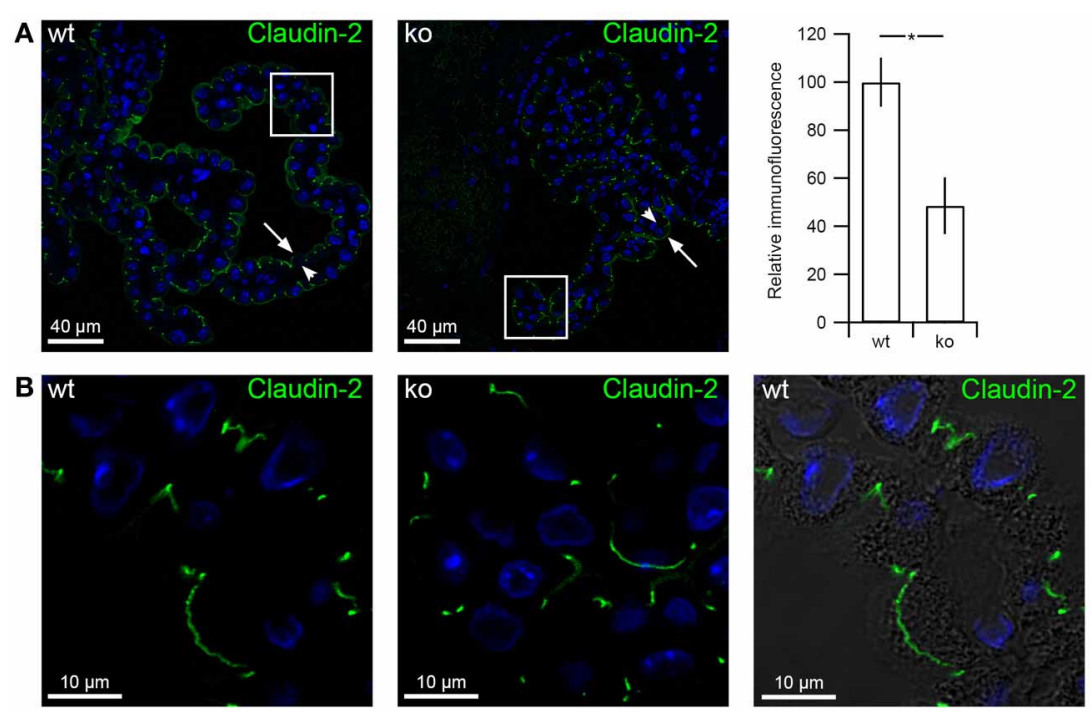

FIGURE 10 | Claudin-2 expression decreases in CPE from slc4a10 ko mice. (A) Immunohistochemical detection of claudin-2 in s/c4a10 wt and ko $\mathrm{CPE}$, as indicated. Bar graph on the right show the semi-quantitation of the immunofluorescence in slc4a10 wt and ko mouse CPE (wt: $n=5, k 0: n=3$ ).
(B) High magnification micrographs of claudin-2 immunoreactivity in s/c4a10 wt and ko CPE, as indicated. Arrows indicate the luminal membrane, while arrowheads indicate the basolateral membrane. *indicates statistical significance. Cell nuclei were visualized by Topro nuclear staining (blue). in slc4a10 wt and ko CPE ( $p=0.686, n=4$ and 4 for wt and ko). Nevertheless, as seen in Figure 9B, the abundance of $\alpha$-catenin is significantly decreased in the slc4a10 ko CPE as compared to the wt (Figure 9B Bar graph, $p=0.0357, n=5$ and 3 for wt and ko, respectively). Furthermore, the cellular localization of $\alpha$-catenin seems to become more abundant in the lateral membrane domain and less in the basolateral labyrinth (Figure 9C). For $\beta$-catenin, similar expression patterns and protein abundances were observed in the two genotypes (Figure 9D, $p=$ $0.143, n=5$ and 3 for wt and ko, respectively).

\section{CLAUDIN-2 ABUNDANCE IN THE CHOROID PLEXUS EPITHELIUM IS DECREASED IN SIC4a10 KO MICE}

Claudin-2 expression in the tight junction of the CPE is most likely a determining factor in paracellular permeability in the epithelium. We hypothesized that decreased expression of ion and water transporters in CPE of slc4a10 ko mice and most likely also decreased CSF secretion capacity would minimize the need for paracellular movement of ions and water molecules through claudin-2. The representative micrographs in Figures 10A,B illustrate that the claudin-2 immunoreactivity in CPE is decreased in slc4a10 ko compared to slc4a10 wt mice. The occasional observations of continuous lines of claudin-2 labeling in the luminal cell domain probably corresponds to tangentially sectioned cells, as judged from the DIC overlay in Figure 10B. The bar graph shows an $\sim 50 \%$ decrease in CPE anti-claudin-2 staining in the slc4a10 ko ( $p=0.0357, n=5$ and 3 for wt and ko, respectively). Thus, it is likely that the capacity for selective movement of certain ions and perhaps water molecules via the paracellular route may be limited in slc4a10 deficient mice.

\section{DISCUSSION}

Previously, we have shown that disruption of the gene encoding the key $\mathrm{Na}^{+}$loader, Ncbe, in the CPE leads to significant changes in both the organization and abundance of other transport proteins (Damkier et al., 2009; Damkier and Praetorius, 2012). Protein abundance of the $\mathrm{Na}^{+}, \mathrm{K}^{+}$-ATPase $\alpha 1$ subunit and AQP1 was markedly reduced in slc4a10 ko, and NHE1 was localized to the basolateral membrane as opposed to the luminal membrane. However, the other $\mathrm{Na}^{+} \mathrm{HCO}_{3}^{-}$cotransporters $\mathrm{NBCn} 1$ and NBCe2 were unaffected in the slc4a10 ko mice. In the current study, we further explored the effects in the slc4a10 ko mice; on the cellular localization and abundance of proteins expected to be involved in the polarization of CPE cells, with emphasis on anchoring and cytoskeletal proteins. Table 2 and Figure 11 are summarizing the subcellular localization of the membrane-, anchoring-, and cytoskeletal proteins located in this and previous studies. We report that AE2 protein abundance is significantly increased in the slc4a10 ko mice and that $\alpha \mathrm{I}$-spectrin protein, which is present mainly in the basolateral membrane in the wt, is almost exclusively located in the apical membrane in the ko. Additionally, the protein abundance of $\alpha \mathrm{I}$-spectrin is decreased in the slc4a10 ko CPE. Furthermore, we show that the protein levels of both claudin- 2 and $\alpha$-catenin are decreased in slc4a10 ko as compared to wt.

Marrs and Alper and their respective co-workers reported that the expression of both ankyrin and spectrin in the CPE was most prominent in the luminal membrane domain of the cells (Marrs et al., 1993; Alper et al., 1994). Here, we show that the mouse CPE expresses only ankyrin- 3 and the $\alpha \mathrm{I}-, \alpha \mathrm{II}-, \beta \mathrm{I}-$, and $\beta$ II-spectrins. The identification of $\alpha$ II- and $\beta$ II-spectrins was anticipated, whereas $\alpha \mathrm{I}$ - and $\beta \mathrm{I}$-spectrins are considered erythroid spectrin forms with additional expression of certain variants in the brain (Machnicka et al., 2012). Ankyrin-3 immunoreactivity was observed in accordance with the two previous studies, and alongside three of the spectrins. However, $\alpha$ I-spectrin was expressed both in the luminal and in the basolateral membrane domain, especially near the basal labyrinth. As spectrins form heterodimers 
Table 2 | Summary of data presented for CPE in the current and two previous studies (Damkier et al., 2009; Damkier and Praetorius, 2012).

\section{SIc4a10 Basal Lateral Labyrinth Luminal}

\begin{tabular}{lll}
\hline \multicolumn{2}{l}{ MEMBRANE PROTEINS } & \\
$\alpha 1 \mathrm{Na}, \mathrm{K}-\mathrm{ATPa} S$ & wt & +++ \\
& ko & + \\
\hline$\beta 1 \mathrm{Na}, \mathrm{K}-$ ATPase & wt & +++ \\
& ko & + \\
\hline
\end{tabular}

\begin{tabular}{|c|c|c|c|c|c|}
\hline \multirow[t]{2}{*}{ AE2 } & wt & + & + & + & \\
\hline & ko & ++ & ++ & ++ & \\
\hline \multirow[t]{2}{*}{ NCBE } & wt & + & + & + & \\
\hline & ko & & & & \\
\hline \multirow[t]{2}{*}{ NHE1 } & wt & & & & + \\
\hline & ko & + & + & + & \\
\hline
\end{tabular}

\begin{tabular}{llc}
\hline $\mathrm{NBCn1}$ & wt & + \\
& ko & + \\
\hline
\end{tabular}

\begin{tabular}{llc} 
NBCe2 & wt & + \\
& ko & + \\
\hline
\end{tabular}

$\begin{array}{lccccc}\text { AQP1 } & \text { wt } & ++ & ++ & ++ & +++ \\ & \text { ko } & + & + & + & + \\ \text { ANCHORING PROTEINS } & & & & \\ \text { Ankyrin-3 } & \text { wt } & & & & + \\ & \text { ko } & & & & +\end{array}$

\begin{tabular}{|c|c|c|c|c|c|}
\hline \multirow[t]{2}{*}{$\alpha$-catenin } & \multicolumn{2}{|l|}{ wt } & + & \multicolumn{2}{|l|}{++} \\
\hline & ko & & + & + & \\
\hline \multirow[t]{2}{*}{$\beta$-catenin } & wt & & + & + & \\
\hline & ko & & + & + & \\
\hline \multirow[t]{2}{*}{$\alpha$-adducin } & wt & + & + & ++ & + \\
\hline & ko & + & + & +++ & \\
\hline
\end{tabular}

\begin{tabular}{llc}
\hline Ezrin & wt & + \\
& ko & + \\
\hline
\end{tabular}

\begin{tabular}{lcc}
\hline Moesin & wt & + \\
& ko & + \\
CYTOSKELETAL PROTEINS &
\end{tabular}

\begin{tabular}{llllll}
$\alpha 1$-spectrin & wt & + & + & ++ & + \\
& ko & & & & ++ \\
\hline$\alpha 2$-spectrin & wt & & + & + & ++ \\
& ko & & + & + & ++ \\
\hline$\beta 1$-spectrin & wt & & + & + & ++ \\
& ko & & + & + & + \\
\hline 32 -spectrin & wt & + & + & + & + \\
& ko & & + & + & (Continued)
\end{tabular}

Table 2 | Continued

\begin{tabular}{llllll}
\hline & SIc4a10 & Basal & Lateral & Labyrinth & Luminal \\
\hline CELL-CELL & INTERACTIONS & & & \\
Claudin-2 & wt & & & & ++ \\
& ko & & & & + \\
\hline E-cadherin & wt & + & + & ++ & \\
& ko & + & ++ & + & \\
\hline
\end{tabular}

The subcellular sites basal, lateral, labyrinth, and luminal cover both the respective parts of the plasma membrane proteins (transporters and cell-cell interaction proteins) and the sub-membrane part of the cytoplasm for soluble cytosolic proteins (anchoring and cytoskeletal proteins).

of $\alpha$ and $\beta$ subunits, our data suggest that both $\beta \mathrm{I}$ and $\beta \mathrm{II}$ could dimerize with $\alpha \mathrm{I}$-spectrin at its basolateral localization although the immunoreactivity for both $\beta$ subunits is weak at this site. We note that ankyrin-3 immunoreactivity, as expected, protrudes into the microvilli of the CPE, where it anchors the $\mathrm{Na}^{+}, \mathrm{K}^{+}$-ATPase and other membrane proteins to the spectrin cytoskeleton. By contrast, none of the spectrin forms were localized to the microvilli and seemed restricted to a subluminal position most likely corresponding to the terminal web. Thus, we are intrigued by the lack of morphological evidence for supposed interaction of ankyrin-3 with spectrin in CPE. In this particular epithelium, the anchoring of luminal membrane proteins to the spectrin cytoskeleton via ankyrin-3 (and other anchoring proteins) appears to be indirect. One might speculate that ankyrin-3 in CPE binds spectrin via microvillar filamentous actin, as $\gamma$-actin staining stretches from the terminal web into these structures.

In order to explain the spatial separation of a basolateral cadherin and an unusually located spectrin in the luminal domain, Marrs and colleagues suggested that the choroid plexus expressed B-cadherin instead of the epithelial isoform, E-cadherin (Marrs et al., 1993). We here confirm recent reports on the expected expression and basolateral localization of E-cadherin in CPE (Lobas et al., 2012). Nonetheless, E-cadherin is now believed mainly to link to the actin cytoskeleton via the catenins and actinin, rather than the mainly luminal domain spectrins (Nelson, 2008). Our results are in accordance with such an organization, where E-cadherin is unaffected by the disappearance of the basolaterally expressed $\alpha \mathrm{I}$-spectrin. Here, $\gamma$-actin was predominantly expressed in the luminal domain, but previous studies have found ample expression of non-myocyte and f-actin forms more broadly in the CPE cells forming a base for immobilization of basolateral membrane proteins (Marrs et al., 1993; Alper et al., 1994; Li et al., 2009). Also, it seems reasonable to state that the adducins take their usual epithelial positions (Baines, 2010) in the CPE, with luminal domain $\alpha / \beta$ dimers and basolateral $\alpha / \gamma$ dimers. We note that $\mathrm{E}$-cadherin is not confined to adherens junctions as described widely (Alberts et al., 2007); it clearly appears to be involved more broadly in cell-cell and cell-matrix interaction. This issue may need further attention from future investigations.

We previously reported a partial disruption of the luminal domain expression of ezrin in CPE from slc4a10 ko mice (Damkier et al., 2009). Here, we extend the finding and show 


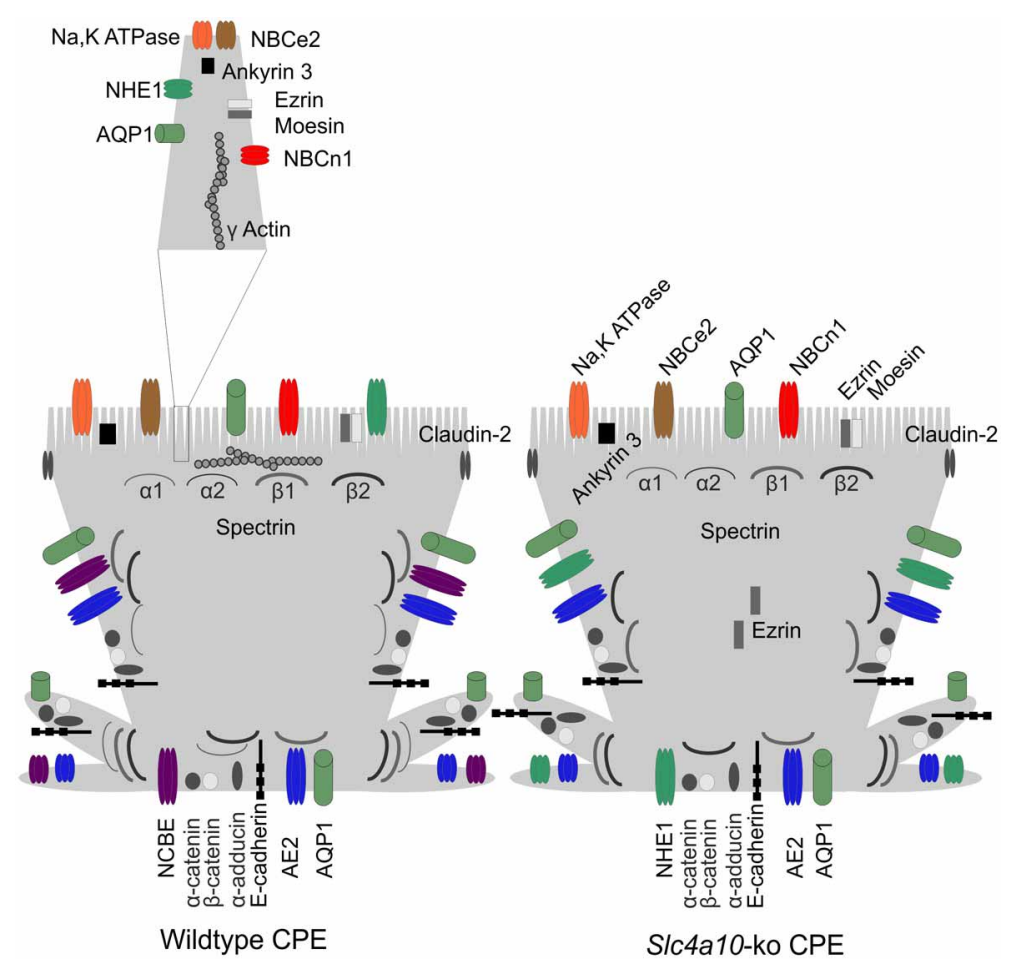

FIGURE 11 | Model of the subcellular position of membrane transporters, cytoskeletal components, and anchoring proteins in the CPE cell from normal and s/c4a10 knockout mice, as indicated. The microvilli are indicated on the luminal membrane and the basal infoldings protrude laterally from the cell basis, separating the basal and the lateral membrane domains. See text for details. that another protein of the ERM complex, moesin, does not redistribute in the same cells. Moesin and ezrin bind membrane proteins or their anchor/scaffolding proteins as well as actin. The explanation for the different staining pattern of these ERM proteins may lie in either of the following characteristics: (1) As opposed to ezrin, moesin has been reported to bind microtubules in addition to actin (Solinet et al., 2013), and (2) only ezrin binds the sodium-hydrogen exchanger regulatory factor (NHERF) (Cha and Donowitz, 2008). The latter is a plausible cause for the more cytosolic ezrin distribution, as the basolateral NHE1 expression in slc4a10 ko CPE minimizes the need for ezrin near the luminal membrane.

The abundance of $\beta 1-\mathrm{Na}^{+}, \mathrm{K}^{+}$-ATPase in slc4a10 ko CPE was decreased to the same extent as we previously reported for the $\alpha 1$ subunit (Damkier and Praetorius, 2012). Ankyrin-3 is most likely a link between the $\mathrm{Na}^{+}, \mathrm{K}^{+}$-ATPase complex and the cytoskeleton in CPE. However, the abundance of ankyrin-3 was not affected by a parallel decrease and remained in the brush border of the epithelium. We speculate that ankyrin-3 is more abundant at the luminal plasma membrane than the $\mathrm{Na}^{+}, \mathrm{K}^{+}$-ATPase in slc4a10 $\mathrm{ko}$, as it plays a role in anchoring other membrane proteins to the actin/spectrin cytoskeleton, such as NKCC1 and NBCe2. The abundance of the $\mathrm{Na}^{+}$independent $\mathrm{Cl}^{-} / \mathrm{HCO}_{3}^{-}$exchanger AE2 in slc4a10 ko was not studied previously. We find a surprising higher abundance of AE2 in the slc4a10 ko, although still with a basolateral localization. The higher AE2 protein level in slc4a10 ko is accompanied by a non-significant trend toward increased $\alpha$-adducin expression. Furthermore, the expression of $\alpha$-adducin seems more pronounced in the basolateral domain, and less apparent in the luminal domain. These findings suggests that the adducin scaffold is altered in the slc4a10 ko CPE compared to the wt, and perhaps consequently increases the stability of AE2 in the basolateral membrane.

The spectrins form a part of the cytoskeleton and also link membrane proteins or their anchor/scaffolding proteins to actin filaments (Baines, 2010). In slc4a10 ko CPE, the distribution of $\alpha \mathrm{I}$-spectrin is profoundly changed from mainly in the basolateral domain to almost exclusively in the luminal domain. This change is observed in parallel to a significant reduction in $\alpha \mathrm{I}$-spectrin abundance. In contrast to $\alpha \mathrm{I}$-spectrin, the cellular localization of $\alpha$ II-spectrin seems more cytoplasmic or basolateral in slc4a10 ko. Thus, it seems that the loss of one $\alpha$-spectrin leads to a replacement with another $\alpha$-spectrin in the basolateral domain, presumably to compensate partly for a decrease in capacity of binding membrane proteins to the spectrin cytoskeleton. The protein abundance of $\alpha \mathrm{II}-, \beta \mathrm{I}$, and $\beta \mathrm{II}$-spectrins in the CPE show no significant change when comparing slc4a10 wt and ko. The mainly luminal domain $\beta$ I-spectrin shows no apparent cellular re-distribution, while the $\beta$ II-spectrin basolateral localization seems slightly decreased.

We speculate that in the basolateral domain it is predominantly $\beta I I-s p e c t r i n$ that dimerizes with $\alpha I$-spectrin and that these spectrins are not required for retaining the proposed adducin-bound AE2 in the basolateral membrane. With regards to the decrease 
of luminal $\mathrm{Na}^{+}, \mathrm{K}^{+}$-ATPase and AQP1 in slc4a10 ko CPE, it is unlikely that changes in spectrins are a primary event in this dysregulation; both $\alpha$-spectrins are maintained in the luminal domain in slc4a10 ko CPE, and only $\beta \mathrm{I}$-spectrin is decreased to a similar degree as the $\mathrm{Na}^{+}, \mathrm{K}^{+}$-ATPase subunits. Interestingly, comparable changes in the CPE expression of $\mathrm{Na}^{+}, \mathrm{K}^{+}$ATPase subunits, Ncbe (slc4a10 gene product), and $\beta I I-s p e c t r i n$ have been reported in slc4a5 ko mice (Kao et al., 2011). As the spectrins form heterodimers (Baines, 2010) it is tempting to suggest that a third type of $\beta$-spectrin is expressed in the luminal domain of slc4a10 ko CPE. However, we observed no $\beta$-spectrins in the cells apart from $\beta$ I and $\beta$ II.

E-cadherin abundance in CPE was unaffected by slc4a10 ko. However, the catenin binding partners seemed slightly less abundant in the ko mice with only $\alpha$-catenin reaching statistical significance. Thus, these proteins do not appear to maintain a fixed stoichiometry in CPE, just as we noted for the hypothesized interactions between $\mathrm{Na}^{+}, \mathrm{K}^{+}$. ATPase/ankyrin-3, NHE1/ezrin/moesin, AE2/ $\alpha$-adducin, and $\alpha$ spectrins $/ \beta$-spectrins. These proteins are not distributed or regulated in parallel with their normal binding partners. In contrast to the stable maintenance of E-cadherin in the cell-cell and cell-matrix interactions, claudin- 2 in the tight junctions was less abundant in the slc4a10 ko CPE. As claudin-2 is involved in transepithelial $\mathrm{Cl}^{-}$and $\mathrm{H}_{2} \mathrm{O}$ transport (Rosenthal et al., 2010), this suggests that the paracellular permeability of $\mathrm{Cl}^{-}$and perhaps even $\mathrm{H}_{2} \mathrm{O}$ is reduced in the ko mice. Both properties would tend to decrease any direct or indirect contribution of paracellular transport to CSF secretion rate (Damkier et al., 2013).

The current investigation does not explain why slc4a10 ko mice do not develop a normal expression level and cellular distribution of spectrins in the CPE. However, it is tempting to speculate that Ncbe recruits $\alpha I / \beta$ II spectrin to the basolateral membrane domain, especially to the basal labyrinth. In the slc4a10 ko CPE, loss of basolateral domain accumulation of $\alpha \mathrm{I} / \beta \mathrm{II}$ spectrin may induce secondary changes in specific parts of the cytoskeleton and anchor proteins that mainly alter luminal membrane proteins AQP1 and $\mathrm{Na}^{+}, \mathrm{K}^{+}$-ATPase, while other proteins at that site, such as NBCn1 and NBCe2, are maintained. Testing this model experimentally seems conceivable using CPE cell culture systems, inducible slc gene knockout, or siRNA mouse models.

In conclusion, the current study does not explain the atypical polarization of the CPE, but we present findings that are inconsistent with fundamental cell biological paradigms developed in epithelial cell types other than CPE. The observations allow the generation of new hypotheses that can be tested experimentally in future studies. Because of the discrepancy between the regulation or cellular distribution among membrane proteins and their usual binding proteins in the CPE, further investigations should focus beyond known protein-protein interactions.

\section{ACKNOWLEDGMENTS}

The authors thank Inger Merete S. Paulsen, Christian V. Westberg, and Helle Høyer for their expert technical assistance. We thank Professor Christian Hübner for slc4a10 ko mouse colony and Professor Pablo Martín-Vasallo for anti- $\beta 1-\mathrm{Na}, \mathrm{K}-$ ATPase antibodies. This work is supported by AUFF AUIdeas, and The Danish Council for Independent Research Medical Sciences (FSS).

\section{REFERENCES}

Alberts, B., Johnson, A., Lewis, J., Raff, M., Roberts, K., and Walter, P. (2007). Molecular Biology of the Cell. New York, NY: Garland Science.

Alper, S. L., Stuart-Tilley, A., Simmons, C. F., Brown, D., and Drenckhahn, D. (1994). The fodrin-ankyrin cytoskeleton of choroid plexus preferentially colocalizes with apical $\mathrm{Na}^{+} \mathrm{K}^{+}$-ATPase rather than with basolateral anion exchanger AE2. J. Clin. Invest. 93, 1430-1438. doi: 10.1172/JCI117120

Baines, A. J. (2010). The spectrin-ankyrin-4.1-adducin membrane skeleton: adapting eukaryotic cells to the demands of animal life. Protoplasma 244, 99-131. doi: 10.1007/s00709-010-0181-1

Bouzinova, E. V., Praetorius, J., Virkki, L. V., Nielsen, S., Boron, W. F., and Aalkjaer, C. (2005). $\mathrm{Na}^{+}$-dependent $\mathrm{HCO}^{3-}$ uptake into the rat choroid plexus epithelium is partially DIDS sensitive. Am. J. Physiol. Cell Physiol. 289, C1448-C1456. doi: 10.1152/ajpcell.00313.2005

Bryant, D. M., and Mostov, K. E. (2008). From cells to organs: building polarized tissue. Nat. Rev. Mol. Cell Biol. 9, 887-901. doi: 10.1038/nrm2523

Cha, B., and Donowitz, M. (2008). The epithelial brush border $\mathrm{Na}^{+} / \mathrm{H}^{+}$exchanger NHE3 associates with the actin cytoskeleton by binding to ezrin directly and via PDZ domain-containing $\mathrm{Na}^{+} / \mathrm{H}^{+}$exchanger regulatory factor (NHERF) proteins. Clin. Exp. Pharmacol. Physiol. 35, 863-871. doi: 10.1111/j.14401681.2008.04931.x

Damkier, H. H., Brown, P. D., and Praetorius, J. (2010). Epithelial pathways in choroid plexus electrolyte transport. Physiology (Bethesda) 25, 239-249. doi: 10.1152/physiol.00011.2010

Damkier, H. H., Brown, P. D., and Praetorius, J. (2013). Cerebrospinal fluid secretion by the choroid plexus. Physiol. Rev. 93, 1847-1892. doi: 10.1152/physrev.00004.2013

Damkier, H. H., Nielsen, S., and Praetorius, J. (2007). Molecular expression of SLC4-derived $\mathrm{Na}^{+}$-dependent anion transporters in selected human tissues. Am. J. Physiol. Regul. Integr. Comp. Physiol. 293, R2136-R2146. doi: 10.1152/ajpregu.00356.2007

Damkier, H. H., and Praetorius, J. (2012). Genetic ablation of Slc4a10 alters the expression pattern of transporters involved in solute movement in the mouse choroid plexus. Am. J. Physiol. Cell Physiol. 302, C1452-C1459. doi: 10.1152/ajpcell.00285.2011

Damkier, H. H., Prasad, V., Hubner, C. A., and Praetorius, J. (2009). Nhe1 is a luminal $\mathrm{Na}^{+} / \mathrm{H}^{+}$exchanger in mouse choroid plexus and is targeted to the basolateral membrane in Ncbe/Nbcn2-null mice. Am. J. Physiol. Cell Physiol. 296, C1291-C1300. doi: 10.1152/ajpcell.00062.2009

Gonzalez-Martinez, L. M., Avila, J., Marti, E., Lecuona, E., and Martin-Vasallo, P. (1994). Expression of the beta-subunit isoforms of the $\mathrm{Na}, \mathrm{K}-\mathrm{ATP}$ ase in rat embryo tissues, inner ear and choroid plexus. Biol. Cell 81, 215-222. doi: 10.1016/0248-4900(94)90003-5

Jacobs, S., Ruusuvuori, E., Sipila, S. T., Haapanen, A., Damkier, H. H., Kurth, I., et al. (2008). Mice with targeted Slc4a10 gene disruption have small brain ventricles and show reduced neuronal excitability. Proc. Natl. Acad. Sci. U.S.A. 105, 311-316. doi: 10.1073/pnas.0705487105

Kao, L., Kurtz, L. M., Shao, X., Papadopoulos, M. C., Liu, L., Bok, D., et al. (2011). Severe neurologic impairment in mice with targeted disruption of the electrogenic sodium bicarbonate cotransporter NBCe2 (Slc4a5 gene). J. Biol. Chem. 286, 32563-32574. doi: 10.1074/jbc.M111.249961

Kashgarian, M., Biemesderfer, D., Caplan, M., and Forbush, B. 3rd. (1985). Monoclonal antibody to Na,K-ATPase: immunocytochemical localization along nephron segments. Kidney Int. 28, 899-913. doi: 10.1038/ki.1985.216

Li, Y. C., Bai, W. Z., Sakai, K., and Hashikawa, T. (2009). Fluorescence and electron microscopic localization of F-actin in the ependymocytes. J. Histochem. Cytochem. 57, 741-751. doi: 10.1369/jhc.2009.953646

Lindsey, A. E., Schneider, K., Simmons, D. M., Baron, R., Lee, B. S., and Kopito, R. R. (1990). Functional expression and subcellular localization of an anion exchanger cloned from choroid plexus. Proc. Natl. Acad. Sci. U.S.A. 87, 5278-5282. doi: 10.1073/pnas.87.14.5278

Lobas, M. A., Helsper, L., Vernon, C. G., Schreiner, D., Zhang, Y., Holtzman, M. J., et al. (2012). Molecular heterogeneity in the choroid plexus epithelium: the 
22-member gamma-protocadherin family is differentially expressed, apically localized, and implicated in CSF regulation. J. Neurochem. 120, 913-927. doi: 10.1111/j.1471-4159.2011.07587.x

Machnicka, B., Grochowalska, R., Boguslawska, D. M., Sikorski, A. F., and Lecomte, M. C. (2012). Spectrin-based skeleton as an actor in cell signaling. Cell. Mol. Life Sci. 69, 191-201. doi: 10.1007/s00018-011-0804-5

Marrs, J. A., Napolitano, E. W., Murphy-Erdosh, C., Mays, R. W., Reichardt, L. F., and Nelson, W. J. (1993). Distinguishing roles of the membrane-cytoskeleton and cadherin mediated cell-cell adhesion in generating different $\mathrm{Na}^{+}, \mathrm{K}^{+}$. ATPase distributions in polarized epithelia. J. Cell Biol. 123, 149-164. doi: 10.1083/jcb.123.1.149

Masuzawa, T., Ohta, T., Kawamura, M., Nakahara, N., and Sato, F. (1984). Immunohistochemical localization of $\mathrm{Na}^{+}, \mathrm{K}^{+}$-ATPase in the choroid plexus. Brain Res. 302, 357-362. doi: 10.1016/0006-8993(84)90250-6

Mellman, I., and Nelson, W. J. (2008). Coordinated protein sorting, targeting and distribution in polarized cells. Nat. Rev. Mol. Cell Biol. 9, 833-845. doi: $10.1038 / \mathrm{nrm} 2525$

Morrow, J. S., Cianci, C. D., Ardito, T., Mann, A. S., and Kashgarian, M. (1989). Ankyrin links fodrin to the alpha subunit of Na,K-ATPase in Madin-Darby canine kidney cells and in intact renal tubule cells. J. Cell Biol. 108, 455-465. doi: $10.1083 /$ jcb.108.2.455

Nelson, W. J. (2008). Regulation of cell-cell adhesion by the cadherin-catenin complex. Biochem. Soc. Trans. 36, 149-155. doi: 10.1042/BST0360149

Nelson, W. J., and Hammerton, R. W. (1989). A membrane-cytoskeletal complex containing $\mathrm{Na}^{+}, \mathrm{K}^{+}$-ATPase, ankyrin, and fodrin in Madin-Darby canine kidney (MDCK) cells: implications for the biogenesis of epithelial cell polarity. J. Cell Biol. 108, 893-902. doi: 10.1083/jcb.108.3.893

Ogando, D. G., Jalimarada, S. S., Zhang, W., Vithana, E. N., and Bonanno, J. A. (2013). SLC4A11 is an EIPA-sensitive $\mathrm{Na}^{+}$permeable pHi Regulator. Am. J. Physiol. Cell Physiol. 305, C716-C727. doi: 10.1152/ajpcell.00056.2013

Plotkin, M. D., Kaplan, M. R., Peterson, L. N., Gullans, S. R., Hebert, S. C., and Delpire, E. (1997). Expression of the $\mathrm{Na}^{+}-\mathrm{K}^{+}-2 \mathrm{Cl}^{-}$cotransporter BSC2 in the nervous system. Am. J. Physiol. 272, C173-C183.

Praetorius, J., and Nielsen, S. (2006). Distribution of sodium transporters and aquaporin-1 in the human choroid plexus. Am. J. Physiol. Cell Physiol. 291, C59-C67. doi: 10.1152/ajpcell.00433.2005

Praetorius, J., Nejsum, L. N., and Nielsen, S. (2004). A SCL4A10 gene product maps selectively to the basolateral plasma membrane of choroid plexus epithelial cells. Am. J. Physiol. Cell Physiol. 286, C601-C610. doi: 10.1152/ajpcell.00240. 2003

Rosenthal, R., Milatz, S., Krug, S. M., Oelrich, B., Schulzke, J. D., Amasheh, S., et al. (2010). Claudin-2, a component of the tight junction, forms a paracellular water channel. J. Cell Biol. 123, 1913-1921. doi: 10.1242/jcs.060665

Solinet, S., Mahmud, K., Stewman, S. F., Ben El Kadhi, K., Decelle, B., Talje, L., et al. (2013). The actin-binding ERM protein Moesin binds to and stabilizes microtubules at the cell cortex. J. Cell Biol. 202, 251-260. doi: 10.1083/jcb. 201304052

Stuart-Tilley, A., Sardet, C., Pouyssegur, J., Schwartz, M. A., Brown, D., and Alper, S. L. (1994). Immunolocalization of anion exchanger AE2 and cation exchanger NHE-1 in distinct adjacent cells of gastric mucosa. Am. J. Physiol. 266, C559-C568.

Wu, Q., Delpire, E., Hebert, S. C., and Strange, K. (1998). Functional demonstration of $\mathrm{Na}^{+}-\mathrm{K}^{+}-2 \mathrm{Cl}^{-}$cotransporter activity in isolated, polarized choroid plexus cells. Am. J. Physiol. 275, C1565-C1572.

Zeuthen, T., and Wright, E. M. (1978). An electrogenic $\mathrm{Na}^{+} / \mathrm{K}^{+}$pump in the choroid plexus. Biochim. Biophys. Acta 511, 517-522. doi: 10.1016/00052736(78)90287-0

Conflict of Interest Statement: The authors declare that the research was conducted in the absence of any commercial or financial relationships that could be construed as a potential conflict of interest.

Received: 30 September 2013; paper pending published: 17 October 2013; accepted: 07 November 2013; published online: 27 November 2013.

Citation: Christensen IB, Gyldenholm T, Damkier HH and Praetorius J (2013) Polarization of membrane associated proteins in the choroid plexus epithelium from normal and slc4a10 knockout mice. Front. Physiol. 4:344. doi: 10.3389/fphys. 2013.00344

This article was submitted to Membrane Physiology and Membrane Biophysics, a section of the journal Frontiers in Physiology.

Copyright (c) 2013 Christensen, Gyldenholm, Damkier and Praetorius. This is an open-access article distributed under the terms of the Creative Commons Attribution License (CC BY). The use, distribution or reproduction in other forums is permitted, provided the original author(s) or licensor are credited and that the original publication in this journal is cited, in accordance with accepted academic practice. No use, distribution or reproduction is permitted which does not comply with these terms. 